OPEN ACCESS

Edited by:

Kristina Bertl,

Malmö University, Sweden

Reviewed by:

Gaetano Isola,

University of Catania, Italy

Renato Correa Viana Casarin,

Campinas State University, Brazi

*Correspondence:

Eliane Porto Barboza

elianeporto.uff@gmail.com

tThese authors have contributed equally to this work

Specialty section

This article was submitted to Periodontics,

a section of the journa

Frontiers in Dental Medicine

Received: 17 January 2021

Accepted: 09 March 2021

Published: 06 April 2021

Citation:

Barboza EP, dos Santos GO Montez C, Sendra LA, Vieira EdO, Carvalho W and Ferreira VF (2021)

Evaluation of Surgical Gown Textiles

for Resistance Against Aerosols: A

Preclinical Double-Blind Study.

Front. Dent. Med. 2:654911. doi: 10.3389/fdmed.2021.654911

\section{Evaluation of Surgical Gown Textiles for Resistance Against Aerosols: A Preclinical Double-Blind Study}

\author{
Eliane Porto Barboza ${ }^{1 *}$, Gustavo Oliveira dos Santos ${ }^{1 \dagger}$, Caroline Montez ${ }^{2 \dagger}$, \\ Luiza Abreu Sendra ${ }^{2 \dagger}$, Esio de Oliveira Vieira ${ }^{1 \dagger}$, Waldimir Carvalho ${ }^{1 \dagger}$ and \\ Vinicius Farias Ferreira ${ }^{2 \dagger}$ \\ ${ }^{1}$ Department of Dental Clinic, Federal Fluminense University School of Dentistry, Niterói, Brazil, ${ }^{2}$ Graduate Program, Federal \\ Fluminense University School of Dentistry, Niterói, Brazil
}

Personal protective equipment is used to prevent healthcare workers from contaminants. With the advent of COVID-19 pandemic, the use of effective PPE becomes more critical to avoiding infection by SARS-CoV-2. This preclinical double-blind study evaluated the performance of surgical gown textiles for penetration resistance against aerosols. The different textiles were divided into seven groups: (1) SMS PP OE Phobic; (2) Laminated Phobic; (3) Medical Barrier; (4) Trilayer Fabric; (5) Impermeable gown; (6) Impermeable with heat sealing tape; and (7) Clean Wear. All groups were exposed to aerosol-generating procedure for $5 \mathrm{~min}$, according to Barboza et al. 2020. All measurements were recorded and exported to a datasheet for analysis using SPSS software. The groups showed significant differences ( $p<0.01)$. Groups 2, 3, 4, 5, and 6 proved to be effective barriers against aerosols and presented a constant behavior. Groups 1 and 7 showed pigmented areas of 13.05 and $48.23 \%$, respectively, suggesting that, in the present test model, these water-repellent and antimicrobial fabrics were not effective barriers against 5 -min aerosols generated by a high-speed dental handpiece. Polyethylene or polyurethane laminated fabrics were efficient against 5-min aerosols. The SMS textile, globally used for surgical gowns, and the cotton fabric, impregnated with nanoparticles, were not effective barriers. The breathability and comfort of these textiles should be tested in future studies. Healthcare workers should be aware of the exact specifications of their surgical gown textiles.

Keywords: SARS-CoV-2, Covid-19, personal protective equipment, health personnel, dental infection control

\section{INTRODUCTION}

The global contamination of thousands of healthcare professionals by SARS-CoV-2 has stimulated research on personal protective equipment-PPE (1), which includes gloves, face shields, aprons, gowns, protective glasses, and masks. With the advent of the COVID-19 pandemic, the use of effective PPE becomes more critical to avoiding contamination and spread of the coronavirus (2-4).

The challenge for some healthcare workers has been even greater due to exposure to aerosolgenerating procedures (5). For these reasons, surgical gowns should be liquid-proof, not only to prevent blood-borne pathogens, but also to protect aerosol particles from penetrating through the protective clothing $(6,7)$. Besides, protective gowns should be breathable to promote comfort of healthcare workers for long hours $(6,8)$. 
TABLE 1 | Characteristics of test groups.

\begin{tabular}{llll}
\hline \multicolumn{2}{l}{ Group Textiles } & \multicolumn{2}{l}{$\boldsymbol{N}=\mathbf{7 0}$ Time of exposure } \\
\hline 1 & SMS $40 \mathrm{~g} / \mathrm{m}^{2}$ & 10 & $5 \mathrm{~min}$ \\
2 & Laminated Phobic $40 \mathrm{~g} / \mathrm{m}^{2}$ & 10 & $5 \mathrm{~min}$ \\
3 & Medical Barrier $60 \mathrm{~g} / \mathrm{m}^{2}$ & 10 & $5 \mathrm{~min}$ \\
4 & Trilayer Fabric $175 \mathrm{~g} / \mathrm{m}^{2}$ & 10 & $5 \mathrm{~min}$ \\
5 & Impermeable gown $50 \mathrm{~g} / \mathrm{m}^{2}$ & 10 & $5 \mathrm{~min}$ \\
6 & Impermeable gown with heat seal tape $50 \mathrm{~g} / \mathrm{m}^{2}$ & 10 & $5 \mathrm{~min}$ \\
7 & Clean Wear $117 \mathrm{~g} / \mathrm{m}^{2}$ & 10 & $5 \mathrm{~min}$ \\
\hline
\end{tabular}

Group 1-SMS PP OE Phobic \#NOTOAS4O (SSMMMS - spunbond, spunbond, meltblown, meltblown, meltblown, spunbond) - Fitesa ${ }^{\circledR}[($ Porto Alegre, Rio Grande do Sul (RS), Brazil)]; Group 2- Laminated Phobic \#B5RHBBK50 (non-woven polypropylene, polyethylene film)-Fitesa ${ }^{\circledR}$ (Porto Alegre, RS, Brazil); Group 3-Medical Barrier \#002 [non-woven polypropylene (Fitesa-Porto Alegre, RS, Brazil), polyethylene film (Nova Embalagens e Filmes Técnicos, Rio de Janeiro, RJ, Brazil)-Mewi (Rio de Janeiro, RJ, Brazil); Group 4-Trilayer Fabric \#21804 (polyester, polyurethane membrane and polyester) - Alpex (Saint Chamond, Loire, France); Group 5-Impermeable gown \#78631 [non-woven polypropylene, polyethylene film [ [Polymer Group Inc. - São José dos Pinhais, Paraná (PR), Brazil)]; Group 6-Impermeable with heat sealing tape \#000017 (non-woven polypropylene, polyethylene film-Cotebras [(São Paulo, São Paulo (SP), Brazil)]; Group 7-Clean Wear \#03 (100\% cotton with nanoparticles)-Nanowear (Novo Hamburgo, RS, Brazil).

Our recent study evaluated three different weights of nonwoven textiles (spunbond 40,60 , and $80 \mathrm{~g} / \mathrm{m}^{2}$ ). The aerosol was able to penetrate all samples in single or folded formats, except for $80 \mathrm{~g} / \mathrm{m}^{2}$ folded. Our findings suggested that healthcare workers exposed to daily aerosol-generating procedures should be aware of the exact specification and performance of the textiles used in the manufacture of their disposable garments (9). If it is not possible to wear an impermeable surgical gown during aerosol-generating procedures, a plastic garment associated with a disposable garment should be worn, as recommended by the World Health Organization (9-11).

This study evaluated the penetration resistance against aerosols of textiles used in the manufacture of surgical gowns.

\section{MATERIALS AND METHODS}

This preclinical double-blind study compared different textiles used to manufacture medical gowns. Seven groups were analyzed (Table 1). All groups were exposed to aerosol-generating procedures for 5 min (Figure 1), according to Barboza et al. (9). All measurements were recorded and exported to a datasheet for analysis using SPSS software (SPSS Statistics for Mac Version 22.0, IBM Corp. Armonk, NY, USA). The measured areas were compared using the Kruskal-Wallis test.

\section{RESULTS}

Table 2 presents the mean, standard deviation, and percentage of pigmented area for each group. The groups presented significant differences $(p<0.01)$. Groups $2,3,4,5$, and 6 showed no pigmented areas, acting as a constant. However, groups 1 and 7 allowed the penetration of aerosol, suggesting that these fabrics, although water-repellent, were not effective barriers. Figure 2 shows pigmentations in groups 1 and 7 after natural drying. Figure 3 shows the distribution of pigmented areas for all groups.

\section{DISCUSSION}

The present work evaluated the penetration resistance against aerosols of different textiles used in the manufacture of medical gowns. With the advent of COVID-19, the challenge of selfprotection by some healthcare workers has been even greater given their exposure to aerosol-generating procedures, their close proximity to the patient, and the impossibility for the patient to wear a mask during the procedure (1-4).

Seven different fabrics commercially used in the manufacture of surgical gowns were analyzed. The samples of SMS (six layers-SSMMMS-Spunbond, Spunbond, Meltblown, Meltblown, Meltblown, Spunbond), globally used in the manufacture of surgical gowns, did not produce an effective barrier against aerosols. Similarly, group 7 was not efficient as a barrier against aerosols. Interestingly, both fabrics are described as water-repellent. The Association for the Advancement of Medical Instrumentation has issued a standard for liquid barrier performance and classification of protective apparel, including surgical gowns (10). Four levels of liquid barrier performance were defined based on liquid impact penetration, hydrostatic pressure, and blood penetration properties using the American Association of Textile Chemists and Colorists (AATCC) tests. The AATCC 42 water resistance impact penetration test determines the ability of a material to resist water penetration under spray impact (11). In addition, the AATCC 127 water resistance hydrostatic pressure test determines the ability of a material to resist water penetration under constant contact with increasing pressure (12). Both tests aim to provide materials certification $(11,12)$. However, the time of exposure to the liquid $(<5 \mathrm{~s})$ by either impact or spray in those tests does not simulate the daily exposure of healthcare workers, especially dentists, to aerosol-generating procedures. The present study is a continuation of our previous work that evaluated three different non-woven weights, in single and folded formats (9). Except for the group of $80 \mathrm{~g} / \mathrm{m}^{2}$ folded, all groups presented pigmented areas ranging from 16.18 to $35.68 \%$, suggesting that the one-layer non-woven textiles were not effective barriers against uninterrupted 5-min aerosol-generating procedures. In both studies, we did not aim to certify the investigated products, but to inform the aerosol barrier property of the product that healthcare workers are possibly purchasing as an item of their PPE. An innovative methodology, simulating a dental procedure, using an aerosol-generating apparatus was used (9). A visual method was chosen to test the capacity of the samples to act as an effective barrier. A better visualization of the area $\left(\mathrm{mm}^{2}\right)$ passing through the textiles and pigmenting the paper sheet was possible by tinting the water with a red dye. Group 1 and 7 resulted in 13.05 and $48.23 \%$ of pigmented areas, respectively (9). Although the methodology used simulates a dental procedure using aerosol from a high-speed dental handpiece, other apparatuses generate aerosols, exposing other professionals such as medical and laboratory workers. 


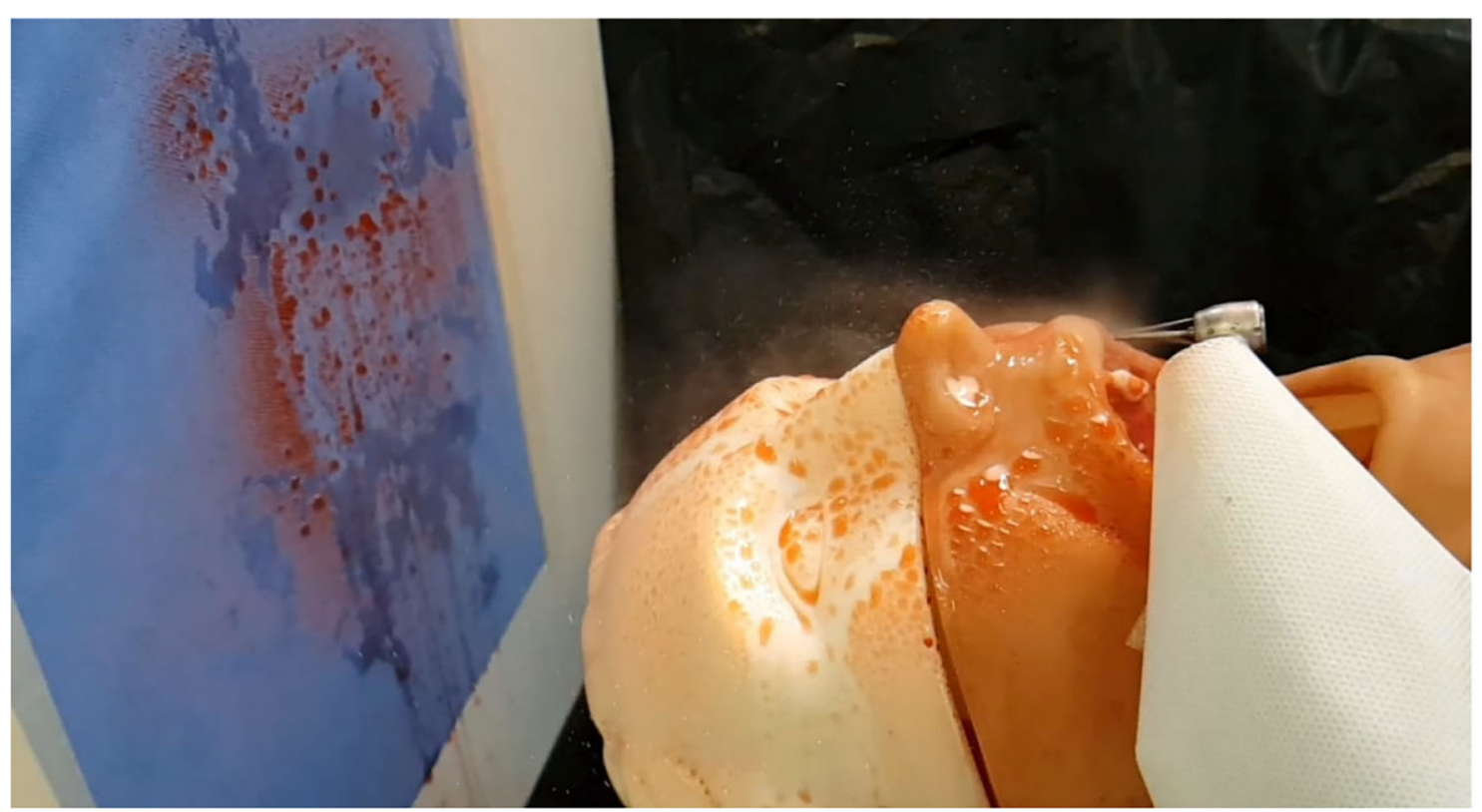

FIGURE 1 | Study model. Note the standardized positions of the mannequin, high speed hand-piece and textile sample (9).

TABLE 2 | Pigmented area mean, standard deviation, and percentage.

\begin{tabular}{lccc}
\hline Group & Mean $\left(\mathbf{m m}^{\mathbf{2}}\right)$ & Standard deviation & Percentage \\
\hline 1 & $7,403.40$ & $7,496.97$ & 13.05 \\
2 & 0 & 0 & 0 \\
3 & 0 & 0 & 0 \\
4 & 0 & 0 & 0 \\
5 & 0 & 0 & 0 \\
6 & 0 & 0 & 0 \\
7 & $27,346.43$ & $3,437.84$ & 48.23 \\
\hline
\end{tabular}

Gowns with barrier protection levels 1, 2, and 3 have specific test requirements. However, gowns with protection levels 1 to 3 can provide increasing resistance to liquids. Only level 4 gowns are tested for viral penetration resistance using the ASTM F1671 test. The present study did not evaluate the microorganism penetration, but groups 4 and 7 presented viral barrier certificates against many bacteria (13). One of the benefits of fabrics with antiviral properties is the reduction of the risk of crosscontamination (14). The impermeable samples containing one layer of polyethylene (groups 2, 3, 5, and 6) or polyurethane (group 4) were effective against aerosols. Group 6, with a heat seal tape in the seams, promoted a better protection. For Unsal et al. (15), the most important factors for textile wettability are surface tension and pore width. Lamination or the use of membranes seems to give textiles waterproof ability (15). Nevertheless, the textile per se can be an efficient barrier. However, a protective barrier can be obtained by associating different materials in specific areas of greater exposure (15).

Another important factor to be considered is textile breathability, which is evaluated by ISO 11092 standards (16). A breathable textile allows healthcare workers to wear PPE comfortably for several hours without excess perspiration and with a significant reduction of the risk of hyperthermia. This factor is essential for a textile to be used in $\operatorname{PPE}(17,18)$. The present study evaluated four polyethylene laminated textiles (groups 2, 3, 5, and 6) and found they are efficient barriers against aerosols. However, the comfort and breathability of the textiles were not evaluated. Group 4 was described as "breathable fabric," according to a certificate of fabric breathability (class 3--180 min of continuous work at a temperature of $25^{\circ} \mathrm{C}$ ). This fabric is composed of polyester, a waterproof and breathable polyurethane membrane, and polyester. The fabric in group 7 (100\% cotton) has also been used in the manufacture of masks, which suggests its breathability. Studies comparing the breathability of fabrics for the manufacture of PPE for healthcare workers have regained popularity as a result of the COVID-19 pandemic. Long hours of work in hospitals require breathable garments.

It should be highlighted that dentists should wear garments that provide barriers against microorganisms and aerosols. This may be different for some physicians, who require only microbial barrier protection. In this context, textiles with different weights and different waterproofing layers should provide the final product with different use capabilities, thereby meeting the needs of each healthcare worker $(14,15)$.

This study only evaluated protection against aerosol penetration. A suction device was not used in this methodology. This could be interpreted as a limitation of this work. However, 


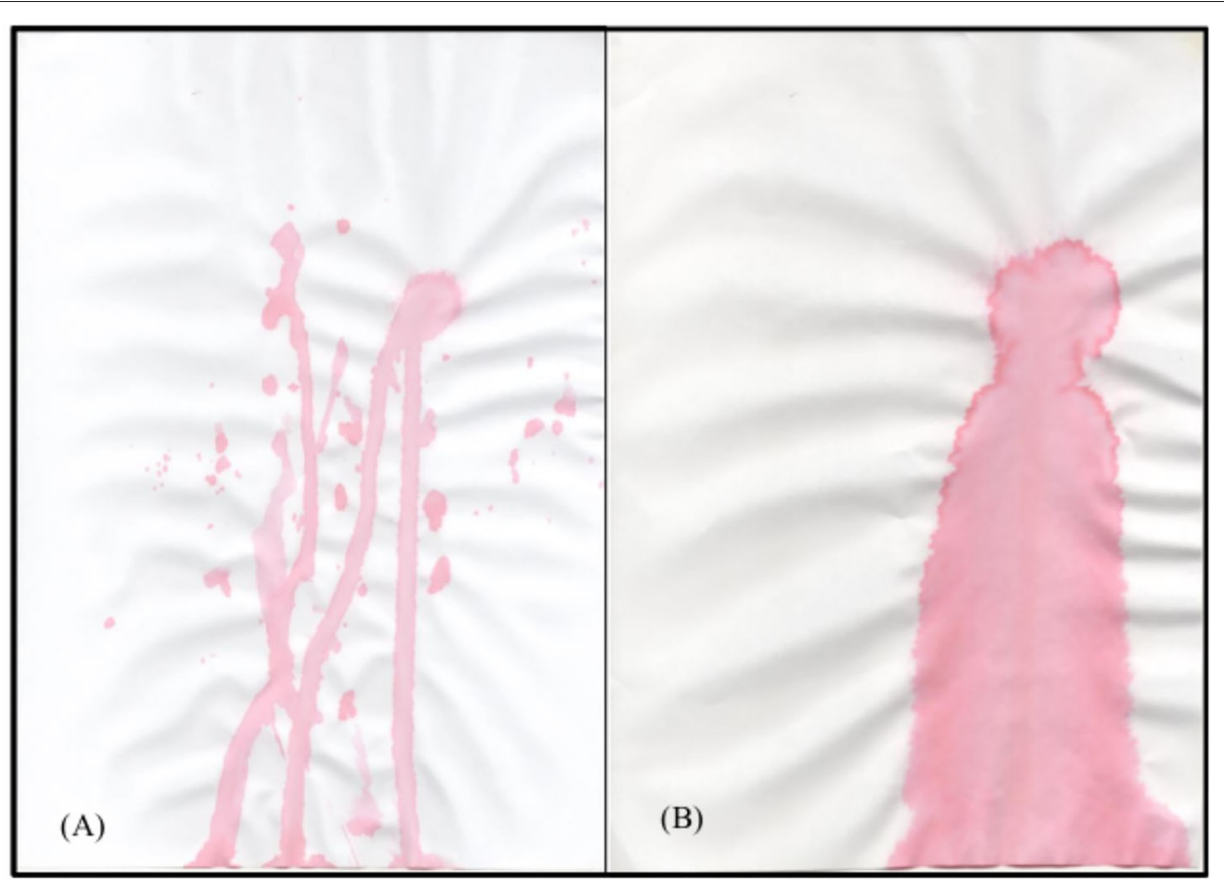

FIGURE 2 | Representative images of pigmentations after natural drying. (A) Group 1; (B) Group 7.

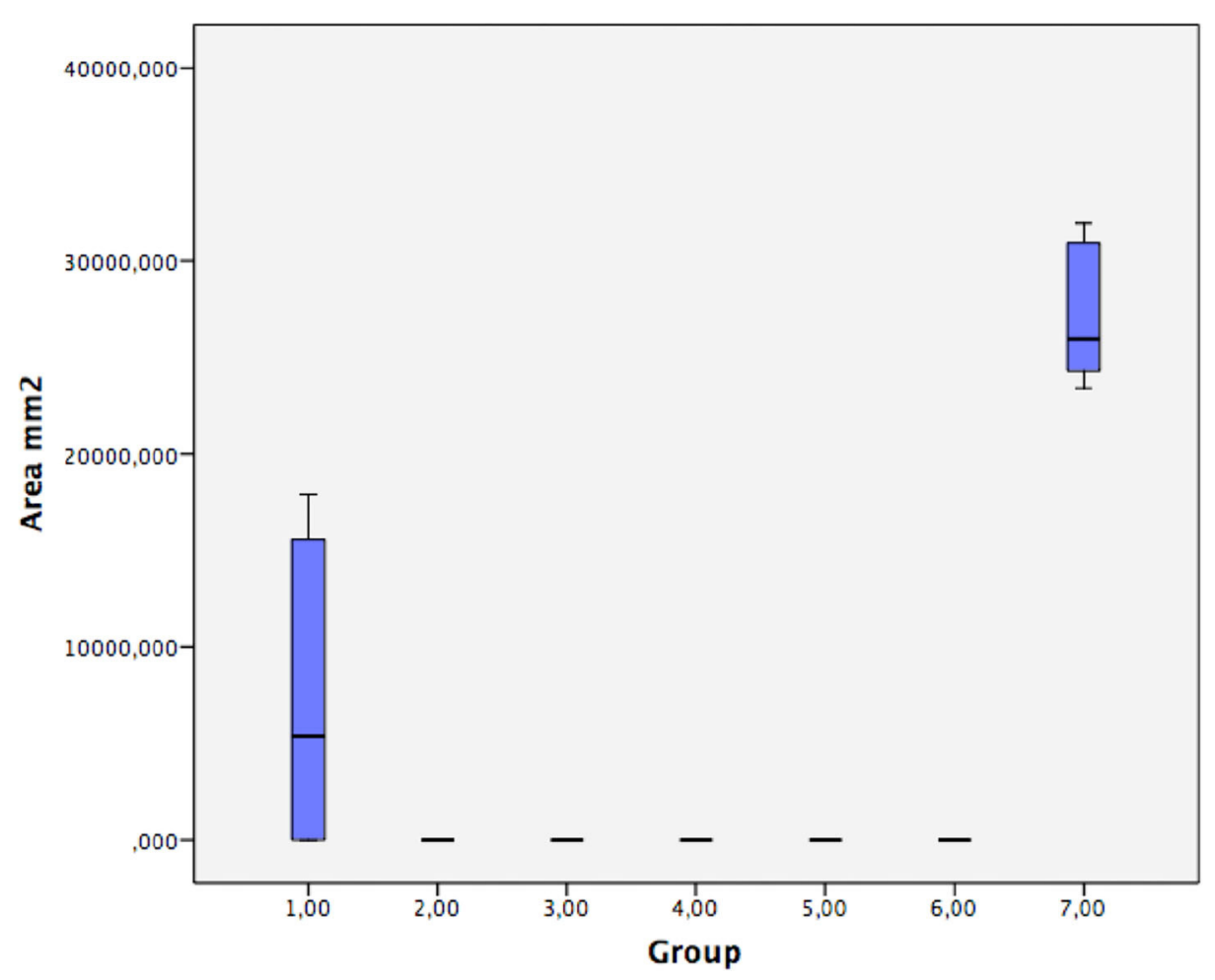

FIGURE 3 | Distribution of pigmented areas for all groups. 
in most countries, suction tip has been used to suction saliva, not the aerosol. A common misunderstanding among many users is that they are protected from body fluids, blood, and other potentially infectious materials when they wear any type of fluid-resistant garment. Water repellency may be mistaken for impermeability. (19) A water-repellent material may allow fluid penetration depending upon the amount of liquid and time of exposure, as shown in the present study. Nevertheless, healthcare professionals who work with aerosols should wear impermeable gowns. Several studies have also reported that when liquid containing microorganisms penetrate a material, microorganisms are carried along with the liquid, and penetration is possible without liquid being visible (20-22). However, future research should test not only the wettability of surgical gown textiles, but also microorganism barrier protection, breathability, and comfort.

\section{CONCLUSION}

The SMS and cotton fabrics impregnated with nanoparticles did not offer protection against aerosols. Non-woven laminated textiles with polyethylene and Trilayer Fabric with a polyurethane membrane proved to be efficient barriers against the 5min aerosol-generating procedure. We suggest that healthcare workers, when exposed to aerosols, be aware of the exact specifications of their surgical gown material, for their safety. If the professional does not have access to an impermeable gown,

\section{REFERENCES}

1. An P, Li L, Chaolong W, Huan G, Xingjie H, Qi W. Association of public health interventions with the epidemiology of the COVID-19 outbreak in Wuhan, China. JAMA. (2020) 323:1915-23. doi: 10.1001/jama.2020.6130

2. Bahl P, Doolan C, de Silva C, Chughtai AA, Bourouiba L, MacIntyre CR. Airborne or droplet precautions for health workers treating COVID-19? J Infect Dis. (2020) jiaa189. doi: 10.1093/infdis/jiaa189

3. World Health Organization-WHO. Infection prevention and control of epidemic- and pandemic-prone acute respiratory infections in health care. 2014. Available online at: https://apps.who.int/iris/bitstream/handle/10665/ 112656/9789241507134_eng.pdf? sequence $=($ accessed June 10, 2020).

4. World Health Organization- WHO. Rational use of personal protective equipment (PPE) for coronavirus disease (COVID-19). (2020) March 19. Available online at: https://apps.who.int/iris/bitstream/handle/10665/331498/ WHO-2019-nCoV-IPCPPE_use- (accessed June 10, 2020).

5. Sabino-Silva R, Jardim ACG, Siqueira WL. Coronavirus COVID-19 impacts to dentistry and potential salivary diagnosis. Clin Oral Invest. (2020) 24:1619-21. doi: 10.1007/s00784-020-03248-x

6. Nurmi S, Lintukorpi A, Saamanen A, Luoma T, Soinnen M, Suikkanen VP. Human, protective cloths and surgical drapes as a source of particles in an operating theatre. Autex Res J. (2003) 3:394-9.

7. Mao N. Methods for Characterisation of Nonwoven Structure, Property, and Performance. Advances in Technical Nonwovens. Leeds: Woodhead Publishing (2016).

8. Garzón-Villalba XP, Wu Y, Ashley CD, Bernard TE. Heat stress risk profiles for three non-woven coveralls. J Occup Environ Hyg. (2018) 15:80-5. doi: 10.1080/15459624.2017.1388514

9. Barboza EP, dos Santos G, Montez C, Sendra LA, Vieira EO, Ferreira VF. Are nonwoven gowns safe for dental professionals? A preclinical double-blind study. Front Dent Med. (2020) 1:577477. doi: 10.3389/fdmed.2020.577477 wearing a plastic garment associated with a disposable gown is mandatory, following the WHO standards $(2014,2020)$.

\section{DATA AVAILABILITY STATEMENT}

The original contributions presented in the study are included in the article/supplementary material, further inquiries can be directed to the corresponding author/s.

\section{AUTHOR CONTRIBUTIONS}

All authors listed have made a substantial, direct and intellectual contribution to the work, and approved it for publication.

\section{ACKNOWLEDGMENTS}

The authors would like to thank Fitesa ${ }^{\circledR}$ (Porto Alegre, RS, Brazil) for the SMS PP OE Phobic and Laminated Phobic samples; EzdocBrazil (Rio de Janeiro, RJ, Brazil) for the Medical Barrier samples; Maior Proteção (Taubaté, SP, Brazil) for the Trilayer Fabric; Cotebras (São Paulo, SP, Brazil) for the impermeable heat seal tape samples, and Nanowear (Novo Hamburgo, RS, Brazil) for the Clean Wear samples. The authors have purchased the impermeable gowns (group 5) from Americanas.com (Brazil). The product is distributed by FA Maringa (Maringá, PR, Brazil).

10. Association for the Advancement of Medical Instrumentation-ANSI/AMMI. Liquid barrier performance and classification of protective apparel and drapes intended for use in health care facilities. 2012. Available online at: https://my. aami.org/aamiresources/previewfiles/pb70_1206_preview.pdf (accessed June 10, 2020).

11. The American Association of Textile Chemists and Colorists-AATCC TM42-2017. Water resistance: Impact penetration test. (2017). Available online at: https://members.aatcc.org/store/tm42/493/ (accessed June 10, 2020).

12. The American Association of Textile Chemists and Colorists-AATCC TM127-2017. Water resistance: Hydrostatic pressure test. (2018). Available online at: https://members.aatcc.org/store/tm127/535/ (accessed June 10, 2020).

13. ASTM F1671 / F1671M-13. Standard Test Method for Resistance of Materials Used in Protective Clothing to Penetration by Blood-Borne Pathogens Using Phi-X174 Bacteriophage Penetration as a Test System. 2013. Available online at: www.astm.org. (accessed June 10, 2020).

14. Parthasarathi V, Thilagavathi G. Developing antiviral surgical gown using nonwoven fabrics for health care sector. Afr Health Sci. (2013) 13:327-32. doi: 10.4314/ahs.v13i2.18

15. Unsal E, Dane JH, Schwartz P. Effect of liquid characteristics on the wetting, capillary migration, and retention properties of fibrous polymer networks. $J$ Appl Polym. (2005) 97:282-92. doi: 10.1002/app.21716

16. International Organization for Standardization - ISO N11092:2014. TextilesPhysN-iological effects-Measurement of thermal and water-vapour resistance under steady-state conditions (sweating guarded-hotplate test). 2013. Available online at: https://www.iso.org/standard/65962.html.

17. Garzón-Villalba XP, Wu Y, Ashley CD, Bernard TE. Ability to discriminate between msustainable and unsustainable heat stress exposures-Part 1: WBGT exposure limits. Ann Work Expos Heal. (2017) 61:611-20. doi: 10.1093/annweh/wxx034 
18. Behera BK, Arora H. Surgical gown: a critical review. J Ind Text. (2009) 38:205-31. doi: 10.1177/1528083708091251

19. The National Personal Protective Technology Laboratory-NPPTL. Considerations for Selecting Protective Clothing used in Healthcare for Protection against Microorganisms in Blood and Body Fluids. (2020). Available online at: https:/www.cdc.gov/niosh/npptl/topics/ protectiveclothing/default.html. (accessed June 10, 2020).

20. McCullough EA. Methods for determining the barrier efficacy of surgical gowns. Am J Infect Control. (1993) 21:368-374. doi: 10.1016/0196-6553(93)90404-R

21. Sakaguchi H, Wada K, Kajioka J, Watanabe M, Nakano R, Hirose $\mathrm{T}$, et al. Maintenance of influenza virus infectivity on the surfaces of personal protective equipment and clothing used in healthcare settings. Environ Health Prev. (2010) 15:344-9. doi: 10.1007/s12199-0100149-y
22. Jones DR, Harris R, Wilson K. Non-woven, disposable theatre gowns for'highrisk'surgery. Ann Roy Coll Surg. (1993) 75:154.

Conflict of Interest: The authors declare that the research was conducted in the absence of any commercial or financial relationships that could be construed as a potential conflict of interest.

Copyright (C) 2021 Barboza, dos Santos, Montez, Sendra, Vieira, Carvalho and Ferreira. This is an open-access article distributed under the terms of the Creative Commons Attribution License (CC BY). The use, distribution or reproduction in other forums is permitted, provided the original author(s) and the copyright owner(s) are credited and that the original publication in this journal is cited, in accordance with accepted academic practice. No use, distribution or reproduction is permitted which does not comply with these terms. 